\title{
Predicting the Perception of Dental Pain Based on Pain Anxiety, Dental Anxiety and Mental Pain in an Iranian Sample: Emphasizing the Type of Patient Complaint
}

\section{Amir abbas taheri}

University of Social Welfare and Rehabilitation Sciences

Ali akbar parvizifard ( $\sim$ parvizali368@gmail.com )

Kermanshah University of Medical Sciences

\section{Sajjad Raeesi Reisi}

Kermanshah University of Medical Sciences

Mahsa Jafari

Ardabil University of Medical Sciences

Khatereh heshmati

Kermanshah University of Medical Sciences

Aliakbar Foroughi

Kermanshah University of Medical Sciences

Masoome Eivazi

Kermanshah University of Medical Sciences

\section{Research Article}

Keywords: Dental anxiety, Mental pain, Pain anxiety, Pain perception

Posted Date: September 13th, 2021

DOI: https://doi.org/10.21203/rs.3.rs-853154/v1

License: (c) (i) This work is licensed under a Creative Commons Attribution 4.0 International License.

Read Full License 


\title{
Predicting the perception of dental pain based on pain anxiety, dental anxiety and mental pain in an Iranian sample: Emphasizing the type of patient complaint
}

\section{Amir Abbas Taheri ${ }^{1}$, Ali akbar Parvizifard ${ }^{2 * *}$, Sajjad Reisi ${ }^{3}$, Mahsa Jafari ${ }^{4}$, Khatereh Heshmati $^{3}$, Aliakbar Foroughi ${ }^{2}$, Masoome Eivazi ${ }^{5}$}

1- Ph.D. student of Department of Rehabilitation counseling, University of social welfare and rehabilitation sciencess, Tehran, Iran

2- Assistant professor, Department of Clinical Psychology, Kermanshah University of Medical Sciences, Kermanshah, Iran

3- Msc in clinical psychology, Department of Clinical Psychology, Kermanshah University of Medical Sciences, Kermanshah, Iran

4- Msc in clinical psychology, Department of Psychology, University of Mohaghegh ardebili, ardebil, Iran

5- Assistant professor, Department of periodontics, school of dentistry, Kermanshah University of Medical Sciences, Kermanshah, Iran

Corresponding author: Ali akbar Parvizifard, Assistant professor, Department of Clinical Psychology, Kermanshah University of Medical Sciences, Kermanshah, Iran, Tell:+989140448661

Gmail: parvizali368@gmail.com

\begin{abstract}
Background: dental pain is one of the most common complaints related to dentistry services. Studies indicate that in addition to the damage to the nerves of teeth, psychological factors affect the perception of pain. This study aims to investigate the psychological factors which influence precepting tooth pain. Moreover, another purpose of the current study is to investigate the impact of some services such as tooth restoration and a root canal on the psychological variables.
\end{abstract}


Methods: The research design was a cross-sectional study by convenience sampling method. The participants were 328 patients who consulted the dentistry clinics in Kermanshah city in 202020201. The used instruments for this study were the Questionnaires of Pain Anxiety (PASS-20), Dental Anxiety (DAI), Mental Pain (OMMP), and Pain Perception (SF-MPQ-2). Finally, the data after being collected were entered into SPSS version 24 and were analyzed using multiple regression analysis.

Results: According to the results of the Pearson correlation coefficient, precepting pain had a significant relationship $(\mathrm{P}=.001)$ with dental anxiety $(\mathrm{r}=0.38)$, pain anxiety $(\mathrm{r}=0.45)$, and mental pain $(\mathrm{r}=0.25)$. Based on the results of simultaneous multiple regression analysis (Enter), dental anxiety variables $(\beta=.266)$, pain anxiety $(\beta=.356)$, and mental pain $(\beta=.139)$ were the significant predictors of precepting pain $(\mathrm{P}<0.05)$. Moreover, in terms of dental anxiety, there was a significant difference between the patients who consult dentistry clinics for root canal services and those whose purposes were receiving other services $(\mathrm{P}<.001)$.

Conclusion: According to the findings of this study, it can be concluded that psychological factors such as dental anxiety, pain anxiety, and mental pain affect precepting dental pain. Further, the kind of received services influences the psychological factors related to dentistry services.

Keywords: Dental anxiety, Mental pain, Pain anxiety, Pain perception

\section{Introduction}

The International Association for the Study of Pain (IASP) defines pain as an unpleasant emotional experience that is related to real or potential risk. Pain as a natural mechanism of the body is a warning to identify and eliminate the source of the pain which may endanger human health. Recently, researches have shown that in addition to the impact of physical factors on appearing the symptoms of pain, psychological factors have undeniable effects on causing and continuity of pain $(1,2)$. The patients who go to dentistry clinics for dental problems will suffer severe pain because of their dental infection and erosion. In addition to the physical factors such as the destruction of dental nerves, psychological factors influence the intensity of precepting pain $(2,3)$. 
According to Melzack's perspective, generally, the intensity of suffering pain is susceptible to the meaning and concept of pain for the patient. These psychological factors which include the ability of precepting and evaluating pain and personal meaning and interpretation of the condition of creating the stimuli are effective in how to respond to the pain (4-6).

Dental patients with pain complaints suffer from different injuries. Some of these complaints are related to tooth decay, root canal, and surgery $(7,8)$. Based on the kind of received services, the degree of precepting pain by the dental patients and the anxiety of received services are different. The patients usually scare and get anxious about the dental environment and the relevant equipment. Fear of dental treatment is common and about $6 \%-15 \%$ of people suffer from dental anxiety $(9,10)$. Dental anxiety has a premature start and the average age of starting this feeling is 12 (10). One study which explored the prevalence of severe dental anxiety among 503 students with different majors revealed that $6.21 \%$ of male students and $24 \%$ of female students suffered from this feeling (10). To describe the specific type of anxiety caused by dentistry, the terminology of dental anxiety is used that is related to fear, anxiety, or stress about the dental environment. Fear of consulting a dentist perhaps results in delay for treatment or prevention of doing so. Some of the symptoms of dental anxiety to conceal anxiety comprise sweating, tachycardia, crying or panic symptoms, retreating and using humor or aggressiveness (11). The etiology of dental anxiety is not well-known and as dental anxiety is a multiple and complex phenomenon, a single agent cannot be the only factor in causing it. Some of the factors that cause and develop this kind of anxiety include personality characteristics, fear of pain, sensitivity to pain, the painful and damaging experience of dentistry especially conditional experiences during childhood in the dental environment, observational learning via observing fear of pain by family members, fear of injury and blood, and coping styles $(11,12)$. The significant consequences of dental anxiety could be fear of the dental environment and avoid going there. Sanikop et al. (2011) in their study found that there is a significant relationship between dental anxiety and perception of pain (13). In another study in which Yaghouti et al. (2012) investigated anxiety and fear among medical students in Rafsanajan asserted that $.83 \%$ of the participants had fear, and $.40 \%$ of them suffered from dental anxiety (14). According to the etiology of dental anxiety and its relationship with fear of pain, it can be an important agent in the continuity of the pain. In addition, based on the theoretical foundation of Melzak about pain, psychological factors such as anxiety affect the kind of precepting the pain. Bushnell et al. (2008) in their research reported that psychological factors such 
as emotions (fear, anxiety) and mood possessed a significant relationship with precepting the pain in dental environments (3).

Mental pain that is a kind of psychological pain, is an overall psychological experience that comprises the concepts of pain and injury but is not conditioned to real physical injury. In other words, it is a wide range of mental experience which is separated from negative emotion moods such as depression and anxiety. Finally, when all the negative emotions become chronic, they can be altered to mental pain and influence the process of pain perception (15). Most of the researches in terms of the correlation of mental pain with suicide and depression claims that mental pain can be effective in predicting suicide and depression (16-18).

The previous studies have shown that there is a relationship between dental anxiety and pain perception (13). Nevertheless, no study has been conducted to investigate that the perception of pain in dental settings has a relationship with mental pain and pain anxiety. Therefore, this study aims to investigate these relationships. Moreover, in the previous researches, the dental patients were not classified based on the kinds of services they receive. Accordingly, the current study classifies these patients as beauty groups, dental decay and restoration, root canal, surgery, and other services. Eventually, the results of this study can be used to establish an appropriate treatment protocol for people who suffer from dental phobia or dental anxiety.

\section{Methodology}

The research design was a cross-sectional study by convenience sampling method .The participants were 350 by the experience of dental pain that referred to dental clinics in Kermanshah city in 2020-2021. As a result, since some of the questionnaires were not filled out properly, 328 of them were analyzed using statistical analysis. After being examined by the dentist and diagnosing their dental problems, the patients were asked to fill out the questionnaires of pain anxiety (PASS-20), dental anxiety (DAI), metal pain (OMMP), and pain perception (SF-MPQ-2). The patients' age ranged from 18 to 53. In the end, after collecting the data, multiple regression analysis was used via SPSS version 24 to investigate psychological factors and the relationship between psychological components about pain and the intensity of precepting pain related to the problems of patients' mouths and teeth. 
This paper has been taken from the project of Kermanshah University of Medical Sciences with the ethical code of IR.KUMS.REC.1398.385. The participants were informed that taking part in this study is voluntary and their informed consent was taken. Further, they got aware of the anonymity and secrecy of this research and they were all satisfied with participating.

\section{Instrument}

Demographic questionnaire: Demographic questionnaire included age, gender, marital status, and academic degree of the participants.

\section{Revised McGill Pain questionnaire (SF-MPQ-2)}

This questionnaire was developed by Dworkin et al. in 2009 to develop and complete the old McGill questionnaire. By adding the symptoms of both types of neuropathic and non-neuropathic pain in 22 articles and improving the response framework and changing it with the range from 010 concerning the intensity of pain, this questionnaire was distributed among 882 people who had various symptoms of pain. Moreover, 226 diabetic patients with neuropathic pain who participated in a random clinical trial, were examined in this study. This questionnaire was a Likert scale with 10 items which comprised three sub-scales that the separating indicators of each subscale were constant pain, various pain, emotional pain, and neuropathic pain. The study of Dworkin et al. (2009) revealed that the findings were the reliability and validity indicator of this questionnaire. The results of exploratory and confirmatory factor analysis stated four subscales of constant pain, various pain, neuropathic pain, and emotional pain. The Chronbach's alpha were reported 0.87, $0.87,0.83$, and 0.86 respectively. Adelmanesh et al. in their research, have validated this instrument for patients with sensitive bowel syndrome. These researchers reported three factors of sensory pain, emotional pain, and neuropathic pain in their study. The Chronbach's alpha with the Iranian version for sensory pain, emotional pain, neuropathic pain, and the whole instrument were $0.87,0.87,0.78$, and 0.92 respectively $(19,20)$.

\section{Dental anxiety questionnaire (DAI)}


The dental anxiety questionnaire developed by Malberg and Hoogstraten is a self-report questionnaire that includes 36 items with a five-point Liker scale in the form of scary remarks about dental settings with the internal consistency ranging from $.96 \%$ to $.98 \%$ using Chronbach's alpha. In addition, Yousefi et al. in Iran examined the psychometric features of this questionnaire over 300 students among the Iranian population. The explored structure among the Iranian population was confirmed via confirmatory factor analysis and it encompassed acceptable psychometric features. Further, the internal consistency analyzed by Chronbach's alpha was .94\% $(21,22)$.

\section{Mental pain questionnaire (OMMP)}

This questionnaire which has been developed by Urbach et al. (2003) includes 44 items and 9 subscales. The alpha coefficient for the nine subscales reported inalterability subscale (0.95), lack of control (0.95), narcissism/worthlessness (0.93), emotional turmoil (0.93), tonic immobility (0.85), alienation (0.79), confusion (0.80), social distancing (0.80), and emptiness $(0.75)$. The other study in Iran conducted by Bagiyan Koulemarzet al. considered the psychometric characteristics of this questionnaire among 300 students among the Iranian population. The exploratory factor analysis highlighted six factors that explained the mental pain variance reporting coefficient alpha for emptiness and worthlessness (0.95), confusion and emotional turmoil (0.89), lack of control (0.87), social distancing and alienation (0.86), and fear of loneliness (0.61). In addition, confirmatory factor analysis was confirmed in six factors (23).

\section{Pain anxiety (PASS-20)}

Pain anxiety symptoms scale PASS-20 developed by McCracken and Dhingra (2002) has been published to measure the fear and anxiety of the patients who suffer from different types of chronic pains. This scale is the short-form of the developed 40 questions in 1992. To standardize the PASS20 scale along with DASS-21 scales, the questionnaires of fear of Tampa movement, catastrophic pain, automatic pain, and pain behavior were applied among 310 injured occupational workers at a large production unit after a week (normally) of injury. The results of exploratory factor analysis revealed the principal components with inclined rotation of the three-factor structure with 55.30\% 
of the explanation of variance. The factors were called avoidance, fear of pain, and physical symptoms respectively. Confirmatory factor analysis presented a more appropriate Adjusted Goodness of Fit Index (AGFI) for the three-factor structure against the four-factor structure of the original version and the one-factor structure. Convergent validity scale with other scales of depression and anxiety, fear of movement, catastrophic pain, and pain behavior were statistically significant. Checking the divergence of the scale with automatic pain indicated a significant negative correlation. The internal consistency coefficient for subscales reported 0.91 for avoidance, 0.87 for fear of pain, and 0.81 for physical symptoms $(24,25)$.

\section{Results}

In this study, 328 patients participated whose mean score and standard deviation (SD) were 32.27 \pm 8.19. The demographic information of the participants has been presented in Table 1 .

As it's obvious in Table 1, 185 (56.4\%) of the participants were female, 217 (66.2\%) of them were married, and 176 (53.7\%) of them had bachelor's degrees and higher education. In Table 2, descriptive indicators for the variables of pain perception, dental anxiety, pain anxiety, and mental pain have been presented based on the reason for visiting the dentist.

According to the results of the Pearson correlation coefficient, precepting pain strongly correlated $(\mathrm{P}=.001)$ with dental anxiety $(\mathrm{r}=0.38)$, pain anxiety $(\mathrm{r}=0.45)$, and mental pain $(\mathrm{r}=0.25)$. Regarding Table 2, the results of simultaneous multiple regression analysis (Enter) have been reported to anticipate pain perception based on predictor variables (dental anxiety, pain anxiety, and mental pain).

Consulting Table 2, the achieved value for tolerance statistics for all three predictor variables were more than the acceptable value (.40\%). In addition, VIF statistics value for predictor variables was nearly 1 which is an acceptable value. Finally, the achieved value for Durbin-Watson Test was in the acceptable range of 1.50 to 2.50 . Therefore, the necessary pre-assumptions for regression analysis have been assumed. Moreover, according to the results of simultaneous multiple 
regression analysis (Enter), the variables of dental anxiety $(\beta=0.266)$, pain anxiety $(\beta=0.356)$, and mental pain $(\beta=0.139)$ were the significant predictors of precepting the pain $(\mathrm{P}<.005)$. Furthermore, the results pointed out that the multiple correlational coefficients among predictor variables were 0.544 for pain perception and 0.294 for the determined coefficient. Thus, the predictor variables of this research were the indicators of $29 \%$ of pain perception variance among the patients who visited dental clinics in Kermanshah.

According to Table 3, the reason for visiting dental clinics for 121 (36.9\%) of the participants were for root canal services. In addition, in Table 3, the mean score, SD for the variables, and the reasons for going to dental clinics have been described. And then, with the use of the one-way Analysis of Variance (one-way ANOVA) test, the difference among mean scores of the variables in relation to the reason of consulting dentist has been investigated. The results of the one-way ANOVA test showed that according to dental anxiety, there is a significant difference among dental anxiety, pain anxiety, and mental pain $(\mathrm{P}<0.05)$ of participants, but according to pain perception, there isn't a significant difference between them $(\mathrm{P}>0.05)$. Therefore, the Scheffe post hoc test was used to study the difference among participants in terms of the variables of dental anxiety, pain anxiety, and mental pain. In Table 4, the results of the Scheffe post hoc test are presented to investigate the between-group differences in terms of dental anxiety, pain anxiety, and mental pain.

As presented in Table 4, about dental anxiety, there was a significant difference between the patients who consult dentist for root canal services and those who received services of teeth beauty, caries and restoration, surgery, and others $(\mathrm{P}<.001)$, and between the patients who got surgery services and those who received other services $(\mathrm{P}<.05)$ there was a significant difference as well. Further, according to pain anxiety, there was a significant difference between the patients who received root canal services and those who got restoration services $(\mathrm{P}<0.05)$.

\section{Discussion}


Pain is a multi-dimension phenomenon and various factors are effective in the incidence of pain and its perception. One kind of pain is dental pain. Most people suffer from toothache and most of them avoid receiving dental services because of distorted fears. The current study aimed to investigate the psychological factors that influence the perception of pain in dental environments. The main purpose of this research was based on the assumption that psychological factors such as dental anxiety, pain anxiety, and mental pain affect the patient's perception of pain. Moreover, the researchers aimed to study the type of services that the patients received and their impact on the perception of the patients' pain. Statistical analysis revealed psychological factors including dental anxiety, pain anxiety, and mental pain strongly correlated with the perception of the pain. Thus, when patients are afraid of dental environments and the services, or when they get involved in the relevant anxiety, they experience a high level of mental pain, and according to McGill Pain Scale, their scores will be much higher.

In the light of the literature review, various researches have reported that there is a relationship between psychological factors and dental pain (26-28). In the same vein, Gabriela (2018) in her study investigated stress, anxiety in perception, and expecting dental pain among children. The results before receiving the intervention, immediately after receiving the intervention, and six months after that stated that stress and anxiety do not affect the perception of the pain immediately during receiving the intervention, but the patients' anticipation of attending dental settings influences their perception of the pain. This result was repeated among old people as well. According to this study of Gabriela and the current study, it can be concluded that mental moods and people's attitudes towards dental intervention affect the perception of pain (29).

Based on regression results, pain anxiety $(\beta=0.356)$ had the most variance of changeability in precepting the pain. By describing this finding, the type of anxiety formation among toothache patients can be studied. In another research, Eli (2004) studied the psychological model of the patients who suffered from dental anxiety. The results asserted that the negative and painful experiences towards dental environments during childhood and the existence of pathological personality traits related to attachment styles are effective in precepting the pain. The people who reported unpleasant experiences of dental environments during their childhood had complaints about having more anxiety in adulthood. In this study (Eli, 2004), the kind of child-parent attachment style was an important predictor of a patient's pain in dental environments. The patients 
who had a safe attachment style in relation to their parents had a more safe relationship with the dentist and reported less anxiety. On the other hand, the people who had insecure attachment styles along with the feel of ambivalence had an insecure relationship with their dentist and suffered from more anxiety. In the same conditions, the people who had safe schema in a child-parent relationship reported less anxiety in comparison with those who had insecure schema. In line with the findings of this study, it could be concluded that formed personality factors of the patient during the growing period can cause pain anxiety as a psychological pattern $(30,31)$.

In describing the findings of this research in terms of the way of affecting psychological factors on pain perception, the following points should be taken into account. The role of positive and negative emotions is one of the factors that influence precepting pain. According to the conducted researches about the emotions of the people who experience positive emotions when encountering situations related to pain, they reported less pain $(3,28)$. On the other hand, those people who had higher negative emotions and endured more mental pain experienced more pain (32). Experimental researches which have manipulated emotional conditions and the moods of the patients in clinical environments via providing pleasant music, aromatic scent, and relaxant pictures and movies pointed out that the patients stayed away from pain and experienced less pain regarding the mentioned stimuli (33). Therefore, it can be concluded that adjusting emotion is one of the factors that affect the management of pain $(34,35)$.

Patients' mood is another factor that influences their perception of pain. Studies have revealed that people who suffer from depression have more complaints about pain. Regarding the important role of emotion and mood in precepting dental pain during checking the patients' complaints, the significant role of psychological factors should be considered $(33,36)$. Further, personality traits are significant factors in reporting pain. For example, catastrophic pain, pain sensitivity, the low threshold of tolerance, and low toleration are the effective factors in precepting pain (3). The kind of perceived pain is influenced by the way the patient interprets the pain. The people who exaggerate the slightest pain of their tooth and are sensitive to the symptoms of pain, over-estimate the pain and suffer it too much $(5,37)$. Another important factor in managing the pain is toleration (38). The people with low toleration have a low tolerance threshold and identify the pain as insufferable $(39,40)$. The other psychological factor that is effective in precepting the patient's pain is fusion with pain. The patients with high mental pain and intensive anxiety see everything 
through the lens of pain and find themselves suffering much pain. In other words, all the aspects of their life will be influenced by pain regardless of the other personality traits. In this situation, psychological interventions such as Acceptance and Commitment Therapy help people make difference between their whole selves and their pain and do not consider the pain as their total existence $(39,41)$.

Furthermore, the patients who received root canal interventions experienced more pain anxiety and dental anxiety, and they avoided medical services more. One of the reasons for this situation can be the suggestibility towards the beliefs and attitudes of other patients who described dental services as more painful when they received root canal services (42). Therefore, in the process of forming attention and recognizing the places to refer to, the patients find more negative attitudes towards the root canal service and describe it with more painful emotions (43). The past dermatological of the person and remembering imagination repeatedly are also effective in more perception of pain (44). Moreover, the longer duration of the root canal, the kind of used equipment, and involvement of the dental nerves at the highest level can be effective in increasing the scores of perceiving the pain.

According to the theoretical background of pain and psychological traits, it can be concluded that dental pain and perceiving pain do not only occur through neural and physiological pathways but the kind of perceiving pain by the patient is effective in experiencing it $(34,45)$. The results of this research help us investigate the psychological factors of the patients which are about avoidance of going to dental clinics due to fear of pain, reducing patients' anxiety in dental clinics, and finally perceiving less pain by the patients.

In the end, the results of this study presented that dental anxiety, pain anxiety, and mental pain are the predictors of dental pain among the participants. Further, the patients who were applicants of root canal more than other services had more dental anxiety and pain anxiety.

The most important limitation of the current study was investigating the impact of psychological factors on the pain perception of the patients before receiving the services. Further researches are proposed to study the attitudes of the patients towards receiving services and their perception of the pain after getting the dental services. It can be assumed that lots of pain anxiety and dental anxiety are the impacts of catastrophic pain and distorted imagination about dental services and after receiving services, the anxiety of the patients will be reduced. 


\section{Declarations}

\section{Compliance with ethical guidelines}

Research involving human participants, human material, or human data, have been performed in accordance with the Declaration of Helsinki.

This paper has been taken from the project of Kermanshah University of Medical Sciences with the ethical code of IR.KUMS.REC.1398.385. The participants were informed that taking part in this study is voluntary and their informed consent was taken. Further, they got aware of the anonymity and secrecy of this research and they were all satisfied with participating.

\section{Funding}

The Kermanshah Medical Sciences Research Committee provided financial support for this project

Conflict of Interest: The authors state that they have no conflict of interest.

\section{Data available}

The data that support the findings of this study are available on request from the corresponding author. The data are not publicly available due to privacy or ethical restrictions.

\section{References}

1. Sluka KA, George SZ. A New Definition of Pain: Update and Implications for Physical Therapist Practice and Rehabilitation Science. Physical Therapy. 2021;101(4):pzab019.

2. Barke A, Korwisi B, Jakob R, Konstanjsek N, Rief W, Treede R-D. Classification of chronic pain for the International Classification of Diseases (ICD-11): results of the 2017 International WHO Field Testing. Pain. 2021.

3. Loggia ML, Schweinhardt P, Villemure C, Bushnell MC. Effects of psychological state on pain perception in the dental environment. Journal of the Canadian Dental Association. 2008;74(7).

4. Chen JS, Kandle PF, Murray I, Fitzgerald LA, Sehdev JS. Physiology, pain. StatPearls [Internet]. 2021.

5. Melzack R, Casey KL. Sensory, motivational, and central control determinants of pain: a new conceptual model. The skin senses. 1968;1:423-43. 
6. Loeser JD, Melzack R. Pain: an overview. The lancet. 1999;353(9164):1607-9.

7. Frencken JE, Peters MC, Manton DJ, Leal SC, Gordan VV, Eden E. Minimal intervention dentistry for managing dental caries-a review: report of a FDI task group. International dental journal. 2012;62(5):223-43.

8. Lewis C, Lynch H, Johnston B. Dental complaints in emergency departments: a national perspective. Annals of emergency medicine. 2003;42(1):93-9.

9. Shim Y-S, Kim A-H, Jeon E-Y, An S-Y. Dental fear \& anxiety and dental pain in children and adolescents; a systemic review. Journal of dental anesthesia and pain medicine. 2015;15(2):53. 10. Buchanan H. Assessing dental anxiety in children: the Revised Smiley Faces Program. Child: care, health and development. 2010;36(4):534-8.

11. Hmud R, Walsh LJ. Dental anxiety: causes, complications and management approaches. J Minim Interv Dent. 2009;2(1):67-78.

12. Hu LW, Gorenstein C, Fuentes D. Portuguese version of Corah's Dental Anxiety Scale: transcultural adaptation and reliability analysis. Depression and Anxiety. 2007;24(7):467-71.

13. Sanikop S, Agrawal P, Patil S. Relationship between dental anxiety and pain perception during scaling. Journal of oral science. 2011;53(3):341-8.

14. YAGHOOTI KM, Sistani F. Dental fear and anxiety among students of Rafsanjan University of Medical Sciences. 2014.

15. Tossani E. The concept of mental pain. Psychotherapy and Psychosomatics. 2013;82(2):67-73.

16. Orbach I, Mikulincer M, Gilboa-Schechtman E, Sirota P. Mental pain and its relationship to suicidality and life meaning. Suicide and Life-Threatening Behavior. 2003;33(3):231-41.

17. Van Heeringen K, Van den Abbeele D, Vervaet M, Soenen L, Audenaert K. The functional neuroanatomy of mental pain in depression. Psychiatry Research: Neuroimaging. 2010;181(2):141-4.

18. Verrocchio MC, Carrozzino D, Marchetti D, Andreasson K, Fulcheri M, Bech P. Mental pain and suicide: a systematic review of the literature. Frontiers in psychiatry. 2016;7:108.

19. Dworkin RH, Turk DC, Revicki DA, Harding G, Coyne KS, Peirce-Sandner S, et al. Development and initial validation of an expanded and revised version of the Short-form McGill Pain Questionnaire (SF-MPQ-2). PAIN®. 2009;144(1-2):35-42.

20. Adelmanesh F, Jalali A, Attarian H, Farahani B, Ketabchi SM, Arvantaj A, et al. Reliability, validity, and sensitivity measures of expanded and revised version of the short-form McGill Pain Questionnaire (SF-MPQ-2) in Iranian patients with neuropathic and non-neuropathic pain. Pain Medicine. 2012;13(12):1631-8.

21. Yousefi R, Piri F. Psychometric properties of dental anxiety inventory. Journal of Mashhad Dental School. 2017;41(1):69-78.

22. Stouthard ME, Mellenbergh GJ, Hoogstraten J. Assessment of dental anxiety: a facet approach. Anxiety, Stress and Coping. 1993;6(2):89-105.

23. Guimarães R, Fleming M, Cardoso MF. Validation of the Orbach \& Mikulincer Mental Pain Scale (OMMP) on a drug addicted population. Social psychiatry and psychiatric epidemiology. 2014;49(3):405-15.

24. PAKNEJAD M, ASGHARI A, RAHIMINEZHAD A, ROSTAMI R, TAHERI A. Factorial structure and psychometric properties of the Pain Anxiety Symptoms Scale (PASS-20). 2014.

25. Roelofs J, McCracken L, Peters ML, Crombez G, van Breukelen G, Vlaeyen JW. Psychometric evaluation of the Pain Anxiety Symptoms Scale (PASS) in chronic pain patients. Journal of behavioral medicine. 2004;27(2):167-83. 
26. Jerjes W, Hopper C, Kumar M, Upile T, Madland G, Newman S, et al. Psychological intervention in acute dental pain. British dental journal. 2007;202(6):337-43.

27. Maggirias J, Locker D. Psychological factors and perceptions of pain associated with dental treatment. Community dentistry and oral epidemiology. 2002;30(2):151-9.

28. Marsac ML, Funk JB. Relationships among psychological functioning, dental anxiety, pain perception, and coping in children and adolescents. Journal of Dentistry for Children. 2008;75(3):243-51.

29. Lamarca GdA, Vettore MV, Monteiro da Silva AM. The influence of stress and anxiety on the expectation, perception and memory of dental pain in schoolchildren. Dentistry journal. 2018;6(4):60.

30. Eli I, Uziel N, Blumensohn R, Baht R. Modulation of dental anxiety-the role of past experiences, psychopathologic traits and individual attachment patterns. British dental journal. 2004;196(11):689-94.

31. Gordon D, Heimberg RG, Tellez M, Ismail AI. A critical review of approaches to the treatment of dental anxiety in adults. Journal of anxiety disorders. 2013;27(4):365-78.

32. Glaros AG, Williams K, Lausten L. The role of parafunctions, emotions and stress in predicting facial pain. The Journal of the American Dental Association. 2005;136(4):451-8.

33. Villemure C, Bushnell CM. Cognitive modulation of pain: how do attention and emotion influence pain processing? Pain. 2002;95(3):195-9.

34. Meeus M. Are pain beliefs, cognitions, and behaviors influenced by race, ethnicity, and culture in patients with chronic musculoskeletal pain: a systematic review. Pain Physician. 2018;21:541-58.

35. Koechlin H, Coakley R, Schechter N, Werner C, Kossowsky J. The role of emotion regulation in chronic pain: A systematic literature review. Journal of psychosomatic research. 2018;107:38-45.

36. Geisser ME, Roth RS, Theisen ME, Robinson ME, Riley III JL. Negative affect, self-report of depressive symptoms, and clinical depression: relation to the experience of chronic pain. The Clinical journal of pain. 2000;16(2):110-20.

37. Sullivan MJ, Neish N. The effects of disclosure on pain during dental hygiene treatment: the moderating role of catastrophizing. Pain. 1999;79(2-3):155-63.

38. Hassett AL, Finan PH. The role of resilience in the clinical management of chronic pain. Current pain and headache reports. 2016;20(6):39.

39. Hadoush H, Alruz S, Kassab M, Roy AN. Non-pharmacological Management of Burnrelated Pain and Distress in Children: A Systematic Review and Meta-Analysis Study. Systematic Reviews in Pharmacy. 2021;12(3):423-38.

40. Sturgeon JA, Zautra AJ. Resilience: a new paradigm for adaptation to chronic pain. Current pain and headache reports. 2010;14(2):105-12.

41. Du S, Dong J, Jin S, Zhang H, Zhang Y. Acceptance and commitment therapy for chronic pain conditions on functioning: A systematic review protocol. Journal of Advanced Nursing. 2021;77(1):417-26.

42. Ives LT, Stein K, Rivera-Cancel AM, Nicholas JK, Caldwell K, Datta N, et al. Children's Beliefs about Pain: An Exploratory Analysis. Children. 2021;8(6):452.

43. Williams AC, Jelsma E, Varner F. The role of perceived thought control ability in the psychological functioning of Black American mothers. American Journal of Orthopsychiatry. 2021;91(2):246. 
44. O'Grady A, Gray-Burrows K, Tahmassebi J. Inside the waiting room: process drama and dramatic distancing for involving children in research on dental anxiety. Arts \& Health. 2021:116.

45. Damsgård E, Dewar A, Røe C, Hamran T. Staying active despite pain: Pain beliefs and experiences with activity-related pain in patients with chronic musculoskeletal pain. Scandinavian journal of caring sciences. 2011;25(1):108-16.

\section{Table 1}

Demographic information of the participants

\begin{tabular}{cccc}
\hline Variables & & Frequency & Frequency percentage \\
\hline Gender & Male & 143 & $43 / 6$ \\
\cline { 2 - 4 } Marital status & Female & 185 & $56 / 4$ \\
\cline { 2 - 4 } & Single & 111 & $33 / 8$ \\
\hline \multirow{2}{*}{$\begin{array}{c}\text { Academic } \\
\text { degree }\end{array}$} & Married & 217 & $66 / 2$ \\
\cline { 2 - 4 } & illiterate & 13 & 4 \\
\cline { 2 - 4 } & $\begin{array}{c}\text { Middle school } \\
\text { and associate degree }\end{array}$ & 42 & $12 / 8$ \\
& $\begin{array}{c}\text { Bachelor's degree } \\
\text { and higher level }\end{array}$ & 176 & $29 / 6$ \\
\hline
\end{tabular}

\section{Table 2}

The results of multiple linear regression analysis (Enter) to predict the perception of the pain based on predictor variables

\begin{tabular}{lcccccc}
\hline \multicolumn{1}{c}{ variable } & $\mathbf{B}$ & $\mathbf{B}$ & $\mathbf{T}$ & P-value & Tolerance & VIF \\
\hline $\begin{array}{l}\text { Constant value } \\
\text { (a) }\end{array}$ & $69 / 051$ & --- & $7 / 212$ & $0 / 001$ & --- & --- \\
\hline Dental anxiety & $0 / 251$ & $0 / 266$ & $5 / 459$ & $0 / 001$ & $0 / 918$ & $1 / 089$ \\
\hline Pain anxiety & $0 / 415$ & $0 / 356$ & $7 / 303$ & $0 / 001$ & $0 / 914$ & $1 / 094$ \\
\hline Mental pain & $0 / 140$ & $0 / 139$ & $2 / 906$ & $0 / 004$ & $0 / 948$ & $1 / 055$ \\
\hline $\begin{array}{l}\text { Model } \\
\text { summary }\end{array}$ & $\mathbf{R}$ & $\mathbf{R}^{2}$ & Adjusted R & $\mathbf{F}$ & P-value & Durbin-Watson \\
\hline
\end{tabular}

Table 3

Descriptive indicators for the variables of precepting pain, dental anxiety, pain anxiety, and mental pain according to the reason of consulting dentist. 


\begin{tabular}{|c|c|c|c|c|c|c|c|c|c|c|}
\hline \multirow{2}{*}{$\begin{array}{l}\text { The reason } \\
\text { for } \\
\text { consulting }\end{array}$} & \multirow{2}{*}{ Frequency } & \multirow{2}{*}{ Percentage } & \multicolumn{2}{|c|}{ Pain perception } & \multicolumn{2}{|c|}{ Dental anxiety } & \multicolumn{2}{|c|}{ Pain anxiety } & \multicolumn{2}{|c|}{ Mental pain } \\
\hline & & & mean & $\mathrm{SD}$ & mean & SD & mean & $\mathrm{SD}$ & mean & SD \\
\hline Beauty & 23 & 7 & $154 / 13$ & $12 / 83$ & $136 / 65$ & $10 / 52$ & $52 / 04$ & $8 / 51$ & 166 & $13 / 49$ \\
\hline $\begin{array}{l}\text { Caries and } \\
\text { restoration }\end{array}$ & 71 & $21 / 6$ & $153 / 44$ & $11 / 69$ & $140 / 23$ & $11 / 57$ & $57 / 96$ & $10 / 69$ & $172 / 58$ & $14 / 11$ \\
\hline Root canal & 121 & $36 / 9$ & $154 / 92$ & $13 / 93$ & $151 / 65$ & $12 / 19$ & $60 / 07$ & $11 / 54$ & $174 / 07$ & $11 / 79$ \\
\hline Surgery & 86 & $26 / 2$ & $152 / 21$ & $13 / 52$ & $144 / 05$ & $12 / 81$ & $58 / 19$ & $11 / 13$ & $175 / 87$ & $12 / 54$ \\
\hline Other & 27 & $8 / 2$ & $152 / 59$ & $8 / 57$ & $135 / 33$ & $15 / 48$ & $52 / 96$ & $8 / 25$ & $168 / 37$ & $11 / 13$ \\
\hline Total & 328 & 100 & $153 / 64$ & $12 / 89$ & $144 / 79$ & $13 / 66$ & $57 / 97$ & $11 / 05$ & $173 / 19$ & $12 / 82$ \\
\hline \multirow{2}{*}{$\begin{array}{l}\text { One-way } \\
\text { ANOVA }\end{array}$} & & & $\mathbf{F}$ & $\begin{array}{c}\mathrm{P}- \\
\text { value }\end{array}$ & $\mathrm{F}$ & $\begin{array}{c}P- \\
\text { value }\end{array}$ & $\mathrm{F}$ & $\begin{array}{c}P- \\
\text { value }\end{array}$ & $\mathrm{F}$ & $\begin{array}{c}\text { P- } \\
\text { value }\end{array}$ \\
\hline & & & $0 / 616$ & $0 / 651$ & $18 / 089$ & $0 / 001$ & $4 / 316$ & $0 / 002$ & $4 / 030$ & $0 / 003$ \\
\hline
\end{tabular}

\section{Table 4}

The results of the Scheffe Post hoc test to study between-group differences in terms of dental anxiety, pain anxiety, and mental pain

\begin{tabular}{ccccc}
\hline \multirow{2}{*}{ variable } & Group 1 & Group 2 & $\begin{array}{c}\text { Difference in } \\
\text { mean }\end{array}$ & P-value \\
\hline \multirow{3}{*}{ Beauty } & & Beauty & $-3 / 57$ & $0 / 837$ \\
\cline { 3 - 5 } & & Root canal & -15 & $0 / 001$ \\
\cline { 3 - 5 } & & Surgery & $-7 / 39$ & $0 / 172$ \\
\cline { 3 - 5 } & & Other services & $1 / 32$ & $0 / 998$ \\
\cline { 2 - 5 } & Caries and & Root canal & $-11 / 428$ & $0 / 001$ \\
\cline { 3 - 5 } & restoration & Surgery & $-3 / 82$ & $0 / 452$ \\
\cline { 3 - 5 } & & Other services & $4 / 89$ & $0 / 553$ \\
\cline { 2 - 5 } & Root canal & Surgery & $7 / 61$ & $0 / 001$ \\
\cline { 3 - 5 } & & Other services & $16 / 32$ & $0 / 001$ \\
\cline { 2 - 5 } & surgery & Other services & $8 / 71$ & $0 / 41$ \\
\hline
\end{tabular}




\begin{tabular}{|c|c|c|c|c|}
\hline \multirow{10}{*}{ Pain anxiety } & \multirow[t]{4}{*}{ beauty } & $\begin{array}{l}\text { Caries and } \\
\text { restoration }\end{array}$ & $-5 / 91$ & $0 / 272$ \\
\hline & & Root canal & $-8 / 03$ & $0 / 033$ \\
\hline & & Surgery & $-6 / 14$ & $0 / 214$ \\
\hline & & Other services & $-0 / 92$ & 0/998 \\
\hline & \multirow{3}{*}{$\begin{array}{l}\text { Caries and } \\
\text { restoration }\end{array}$} & Root canal & $-2 / 12$ & $0 / 789$ \\
\hline & & Surgery & $-0 / 23$ & $0 / 997$ \\
\hline & & Other services & $4 / 99$ & $0 / 386$ \\
\hline & \multirow[t]{2}{*}{ Root canal } & Surgery & $1 / 89$ & $0 / 821$ \\
\hline & & Other services & $7 / 11$ & $0 / 052$ \\
\hline & surgery & Other services & $5 / 22$ & $0 / 313$ \\
\hline \multirow{10}{*}{ Mental pain } & \multirow[t]{4}{*}{ beauty } & dental filling & $-6 / 58$ & $0 / 317$ \\
\hline & & Root canal & $-8 / 07$ & $0 / 096$ \\
\hline & & Surgery & $-9 / 87$ & $0 / 27$ \\
\hline & & Other services & $-2 / 37$ & $0 / 979$ \\
\hline & \multirow{3}{*}{$\begin{array}{l}\text { Caries and } \\
\text { restoration }\end{array}$} & Root canal & $-1 / 50$ & $0 / 959$ \\
\hline & & Surgery & $-3 / 295$ & $0 / 616$ \\
\hline & & Other services & $4 / 21$ & $0 / 702$ \\
\hline & \multirow[t]{2}{*}{ Root canal } & Surgery & $-1 / 798$ & 0/906 \\
\hline & & Other services & $5 / 704$ & $0 / 341$ \\
\hline & surgery & Other services & $7 / 50$ & $0 / 124$ \\
\hline
\end{tabular}

